PROFESSOR, POR QUE MEU TERMÔMETRO NÃO FUNCIONA?

Cleidson S. de Oliveira

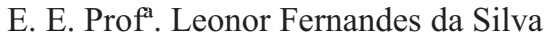

Salto - SP

James A. de Souza

Departamento de Física - UFSCar

São Carlos - SP

\title{
Resumo
}

Atualmente é comum encontrar livros didáticos de Ciências, particularmente de Física, que apresentem alguma proposta experimental para ser trabalhada em sala de aula, ou até mesmo fora dela, pelos alunos. Isso se deve muito à importância dada, por pesquisadores e professores, à experimentação no processo de ensinoaprendizagem dessa disciplina. No entanto, usualmente encontramos, nos roteiros sugeridos por esses materiais, problemas que podem comprometer a realização da prática. A decepção com um experimento que não funcionou adequadamente pode levar muitos docentes e estudantes a perderem o interesse por esse tipo de atividade. Neste trabalho, investigamos um guia experimental problemático, o qual sugere a construção de um termômetro de coluna líquida. Após discutirmos seus problemas, fizemos uma otimização do processo apresentando a riqueza que um simples experimento pode trazer se bem conduzido por um roteiro adequado. $O$ objetivo deste trabalho é incentivar professores e futuros docentes a investigarem as razões do mau funcionamento de um experimen-

\footnotetext{
+ Teacher, why can't my thermometer work?

* Recebido: março de 2011.

Aceito: maio de 2011.
} 
to, transformando uma circunstância de fracasso em uma rica e prazerosa situação de aprendizagem.

Palavras-chave: Atividade experimental. Roteiro experimental problemático. Prática investigativa. Construção de um termômetro didático.

\begin{abstract}
Nowadays, it is common to find Science textbooks, particularly in Physics, exposing some experimental proposal to be executed in the classroom or outside it, by students. This owes to the importance of the experimentation of the teaching and learning process in Physics, given by researchers and Physics faculty. However, many problems suggested in the experimental guides of these materials may compromise the achievement of this purpose, are commonly found. Disappointments with an experiment that does not work properly can lead many teachers and students to lose the interest in this type of activity. In this paper we investigate a problematic experimental guide, which suggests the construction of a liquid column thermometer. After discussing their problems, we present some optimizations of the process showing that a simple experiment is an inexhaustible source of knowledge if it is well conducted by an appropriate route. We hope, therefore, encourage teachers and future teachers to investigate the reasons for the malfunction of an experiment, transforming a condition of failure in a rich and enjoyable learning situation.
\end{abstract}

Keywords: Experimental activity. Problematic experimental guide. Investigative practice. Construction of a didactic thermometer.

\title{
I. Introdução
}

A importância da atividade experimental (AE) para o Ensino de Ciências é reconhecida há muito tempo por professores e pesquisadores dessa área. Por seu caráter motivador, ela pode estimular o aluno a engajar-se no conteúdo que está sendo abordado, favorecendo a aprendizagem dos métodos e conceitos próprios da 
ciência (ALVES; STACHAK, 2005; LABURÚ, 2006). Embora a AE não seja por si só suficiente para a aprendizagem, a literatura aponta que estudantes que têm aulas teóricas com suporte experimental, seja na metodologia tradicional ou em metodologias mais progressistas, apresentam melhores índices de aprendizagem (BARBOSA; PAULO; RINALDI, 1999; MORAES, A.; MORAES, L., 2000). Há também uma série de habilidades e competências - como refletir e analisar criticamente, interagir socialmente, propor e verificar hipóteses, planejar e fazer experimentos, argumentar e debater ideias, realizar e registrar medidas e observações, elaborar relatórios, selecionar variáveis, estabelecer relações, entre outras - que podem ser desenvolvidas pelos alunos, dependendo de como a AE é abordada em sala de aula.

Atualmente, a maioria dos livros, apostilas ou cadernos didáticos de Física, principalmente do Ensino Médio (EM), traz propostas de AE's na tentativa de incentivar o envolvimento de professores e alunos nessas práticas, visando um ensino mais proveitoso e satisfatório.

No entanto, é comum que professores e alunos se deparem com algum tipo de problema presente nesses roteiros, tais como falta de informações, ilustrações fora de escala e até mesmo sugestões de materiais inapropriados. Se o professor ou aluno seguirem passo a passo as instruções de um roteiro problemático, certamente obterão como resultado um experimento que não funciona adequadamente. Em certos casos, devido à escassez de aulas, a experimentação é realizada pelos alunos como tarefa de casa, deixando para a sala de aula as discussões sobre a prática. O resultado, comumente se reduz à pergunta: professor, por que o meu experimento não funciona?

Situações como essas podem se tornar muito ricas para o processo de ensino-aprendizagem se os professores e alunos se dispuserem a investigar as causas do "fracasso experimental". Esse trabalho de investigação, se bem articulado, poderá contribuir não só para a aprendizagem conceitual, como também para a aprendizagem procedimental e atitudinal. Pela confiança depositada nos materiais didáticos, nem sempre o professor se dispõe a explorar essa situação com seus alunos. Nesse caso, o resultado pode ser a frustração e até mesmo um sentimento de incapacidade de ambas as partes: o de não conseguir ensinar e o de não conseguir aprender Física, mistificando a análise experimental como algo muito complicado e restrito a "mentes brilhantes".

Por essas e outras razões, qualquer roteiro experimental, principalmente aqueles fortemente estruturados (montagem), deve apresentar objetivos bem definidos, sugerir e especificar com clareza os materiais necessários, de preferência aqueles que sejam acessíveis aos docentes e alunos, descrever com detalhes cada 
etapa da montagem experimental apontando soluções alternativas aos problemas que possam ocorrer, apresentar esquemas explicativos e de montagem em escala real, sempre que possível, e ter um grau de complexidade compatível com o nível cognitivo dos estudantes.

Neste trabalho, será apresentada uma investigação de um roteiro experimental problemático comum em livros de Física do EM, o qual sugere a construção de um termômetro de coluna líquida. O objetivo principal é estimular a curiosidade dos leitores, professores e alunos, a investigarem as razões do mau funcionamento de um experimento que pode ter sido comprometido por um roteiro inadequado. Inicialmente, seguiremos o roteiro passo a passo, analisando e apresentando seus problemas, principalmente em relação ao procedimento experimental. Em seguida, faremos uma otimização do processo apresentando a riqueza que um simples experimento pode trazer se bem conduzido por um roteiro adequado. Apresentamos, também, alguns resultados obtidos por alunos do EM ao seguirem o roteiro problemático e um roteiro apropriado para a realização da atividade.

\section{Observando problemas}

O experimento analisado nesta seção pode ser encontrado em vários livros didáticos. O roteiro escolhido é proposto no Caderno de Física do EM (2 ${ }^{\mathrm{a}}$ série, volume 1), elaborado pela Secretaria da Educação do Estado de São Paulo (SEESP). Esse material é composto por duas partes, a do professor - Caderno do Professor (CP), e a do aluno - Caderno do Aluno (CA). O Caderno de Física tem sido utilizado em toda a rede estadual de ensino desde 2008, o que justifica nossa escolha.

O CP possui informações e orientações complementares com relação ao uso do material e a realização das atividades propostas em cada situação de aprendizagem, como o tempo previsto para a realização do experimento, os temas e conteúdos a serem trabalhados, as competências e habilidades a serem desenvolvidas, estratégias, recursos e avaliação direcionadas somente ao professor. No CA são feitas algumas provocações iniciais com perguntas referentes a fenômenos relacionados com a atividade proposta. Os roteiros de experimentação seguem, basicamente, o mesmo padrão em ambos os cadernos, com algumas diferenças na sugestão de materiais. O roteiro analisado faz parte da situação de aprendizagem 3: Construindo um termômetro (p. 9 - 11 do CA e p.15-20 do CP).

$\mathrm{O}$ experimento do termômetro foi escolhido pela sua simplicidade descritiva e pela variedade de materiais, que podem ser utilizados para sua construção, 
sendo acessível a qualquer professor e aluno do EM. Outro fator, mais preocupante, está relacionado à quantidade de equívocos e insuficiência de conteúdo informativo encontrados nos esquemas de montagem e até mesmo a impossibilidade de calibração do termômetro com as técnicas e os materiais sugeridos no roteiro. Esses problemas também foram verificados por outros professores de Física da rede estadual de ensino e compartilhados conosco.

Conforme o $\mathrm{CP}$, os objetivos desta atividade são os seguintes (SÃO PAULO (Estado), 2009, Caderno do Professor): objeto;

- construção de um aparelho simples para medir a temperatura de algum

- possibilitar a discussão sobre outros instrumentos que também têm a finalidade de medir temperatura;

- com a observação da dilatação do líquido termométrico (álcool), o professor terá oportunidade de discutir o comportamento dos materiais sob o efeito da temperatura;

- situações do cotidiano envolvendo o fenômeno da dilatação térmica, como as juntas de dilatação deixadas na construção das linhas férreas ou até mesmo na estrutura de prédios, a dilatação de portões metálicos no verão, entre outras, poderão ser exploradas em sala de aula.

Nota-se, portanto, que o Caderno é bastante claro quanto aos propósitos do experimento. Para verificar se esses objetivos são factíveis com essa atividade, analisaremos o roteiro experimental por partes. O foco será dado ao Caderno do Aluno (CA).

\section{Parte 1: Materiais}

A Fig. 1 mostra uma introdução ao assunto e a lista de materiais sugeridos pelo roteiro de experimentação do caderno do aluno (SÃO PAULO (Estado), 2010, Caderno do Aluno). Na relação de materiais, é importante chamar a atenção para dois fatores: primeiramente, é muito difícil encontrar potes transparentes com a finalidade de guardar filmes fotográficos. Em geral, eles são pretos ou leitosos. Também não é feita nenhuma referência quanto à capacidade do pote e o porquê dele ser de plástico, uma vez que os termômetros comerciais são de vidro. Frascos de remédio, que é a outra opção sugerida, podem ser encontrados com diferentes capacidades. Será que qualquer frasco transparente seria útil para essa atividade? Outro fator é que o roteiro não sugere nenhuma cola específica, o que nos faz acreditar, equivocadamente, que qualquer cola possa ser utilizada nesse experimento. 
Existem algumas diferenças na sugestão de materiais entre os cadernos do professor e do aluno que podem ser comprometedoras para o sucesso da atividade. No CP, há as seguintes sugestões: cola quente para fazer a vedação e um tubo de ensaio como alternativa ao pote de filme fotográfico. Se os alunos tiverem dúvidas a respeito do termômetro que montaram utilizando o CA, fica complicado para o professor discutir os problemas que apareceram, já que os materiais utilizados por ele durante a construção podem ser diferentes. Em uma atividade experimental isso é inviável porque não são feitos comentários no roteiro a respeito das diferenças que podem aparecer nos resultados pela utilização de materiais diversos. Nesse caso, o professor acaba não tendo controle sobre as variáveis que os alunos estão trabalhando.

\section{ROTEIRO DE EXPERIMENTAÇĀO}

\footnotetext{
Como se realiza a medida de temperatura? Como os termômetros funcionam? Para responder a essas perguntas e aprofundar a compreensáo acerca do conceito de temperatura e as propriedades térmicas de diferentes materiais, você vai construir um termômetro caseiro. Organize o material e siga as instruçốes para construir seu termômetro.
}

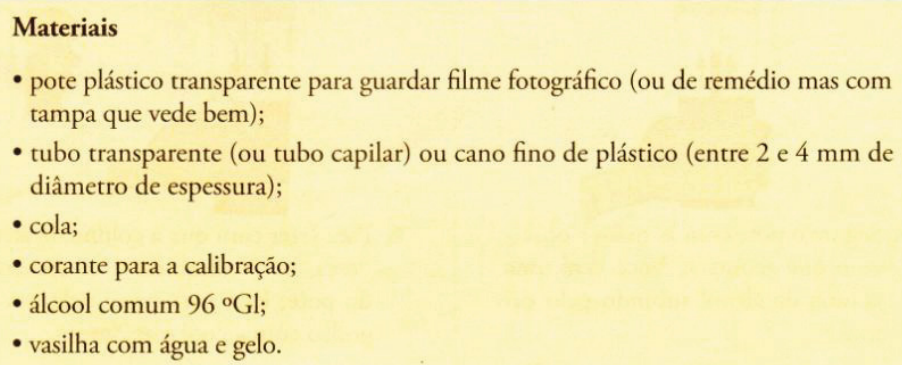

Fig. 1 - Introdução e lista de materiais sugeridos pelo roteiro de experimentação da situação de aprendizagem 3 do Caderno do Aluno.

Fonte: SÃO PAULO (Estado), 2010, Caderno do Aluno.

\section{Parte 2: Mãos à obra!}

\section{Itens 1 e 2}

A Fig. 2 mostra o procedimento de vedação da junção entre o tubo e a tampa do pote. É importante salientar a necessidade da vedação nesta junção, como afirmado no item 2 do roteiro, pois, se esta não ocorrer de maneira efetiva, não será 
possível observar a dilatação do líquido pelo tubo transparente. No entanto, no CA não é feita nenhuma menção sobre o tipo de cola que deve ser utilizada para uma boa vedação. Pela figura do roteiro, somos induzidos a utilizar a cola simples de acetato de polivinila (cola branca). Contudo, ao realizarmos esse experimento, verificamos que esse tipo de cola não é adequado para essa finalidade por não aderir a superfícies plásticas. No CP é sugerida a utilização de cola quente, que pode ser uma boa opção. Outra cola testada e que se mostrou muito eficiente para a vedação foi a Araldite 10 minutos. É uma cola fácil de ser preparada e manuseada e de secagem muito rápida.

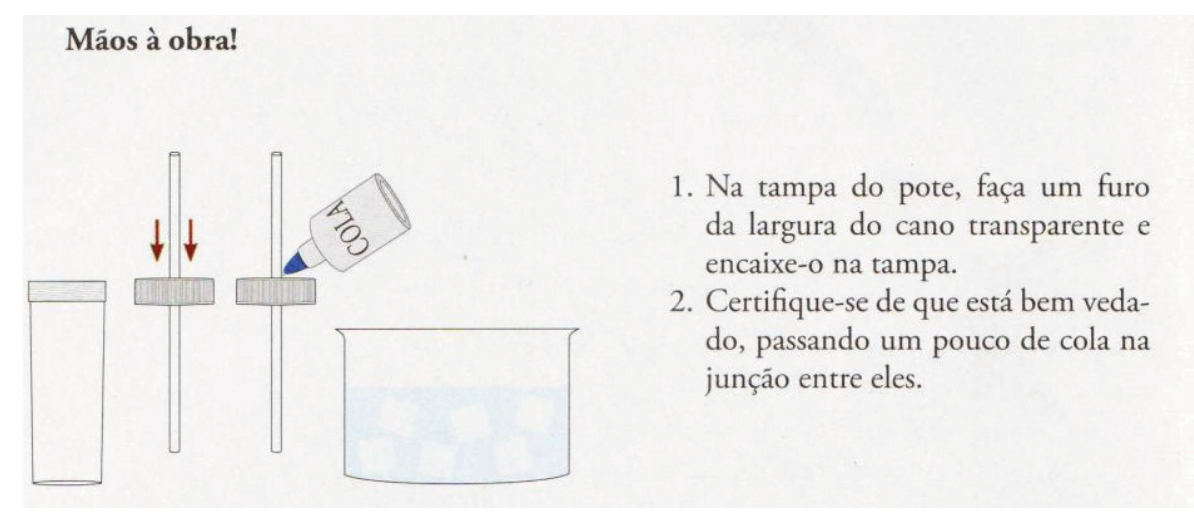

Fig. 2 - Procedimentos 1 e 2 do roteiro de experimentação da situação de aprendizagem 3 do Caderno do Aluno.

Fonte: SÃO PAULO (Estado), 2010, Caderno do Aluno.

\section{Itens 3 e 4, 5 e 6}

Na Fig. 3, observa-se que o procedimento 3 sugere que o pote de filme fotográfico, que faz o papel do bulbo do termômetro, seja preenchido até a metade com álcool. Portanto, o volume interno do frasco passa a ter duas substâncias: álcool e ar com, aproximadamente, o mesmo volume. $\mathrm{O}$ ar no interior do pote contribui para que o movimento do líquido no interior do canudo transparente se torne mais visível quando o sistema é aquecido ou resfriado. No CP, há uma observação referente a este processo, que diz o seguinte (SÃO PAULO (Estado), 2009, p. 19, Caderno do Professor): ... segure o pote pela parte vazia. O que acontece com a velocidade de crescimento da coluna de líquido? Ela subirá mais rápida ou mais lentamente do que quando você segura o pote pela parte cheia de álcool? 
Esse procedimento seria bem apropriado se o objetivo da atividade consistisse apenas na observação do fenômeno da dilatação (contração) térmica do sistema ar/líquido dentro do pote, veja Fig. 4. A presença de ar no interior do pote acaba comprometendo a calibração do termômetro, inviabilizando o seu funcionamento, como veremos na discussão dos itens 7, 8 e 9. Comparativamente, os leitores do roteiro poderiam perguntar o porquê da presença de ar no interior do bulbo, uma vez que, nos termômetros comerciais, isso não é observado.

Outro fator que devemos assinalar está relacionado às figuras ilustrativas dos procedimentos 3, 4, 5 e 6, veja Fig. 3 e 4. Nota-se que o pote utilizado como bulbo tem praticamente o mesmo tamanho do frasco de álcool, mas o pote de filme fotográfico (ou frasco de remédio) sugerido na lista de materiais tem, normalmente, algo em torno de $5 \mathrm{~cm}$; bem menor que frascos de álcool vendidos no comércio. Há, portanto, um problema de escala nessa figura, que pode induzir os estudantes a utilizarem como bulbo recipientes bem maiores do que aqueles sugeridos no roteiro, como um copo, por exemplo. Para se ter ideia do problema, em uma das salas de aula em que a atividade foi realizada, um grupo de alunos utilizou um pote de maionese. Porém, mesmo que seja utilizado um pote maior, é possível ver o efeito do líquido subindo e descendo pela coluna. $\mathrm{O}$ volume do pote tem grande influência no processo de calibração do termômetro.

Ilustrações fora de escala, às vezes, são necessárias para melhorar a visibilidade e o entendimento de certos detalhes em um experimento, como encaixes, ou na explicação de fenômenos na escala atômica, por exemplo. Sempre que possível, tais situações devem ser informadas para que os leitores não cometam enganos conceituais ou comparativos.

3. Agora, encha o pote até a metade com álcool e pingue algumas gotas de corante, para deixá-lo bem colorido.

4. Feche o pote com a tampa, deixando uma das extremidades do canudo imersa no álcool.

Atençáo! É preciso vedar muito bem, pois do contrário o experimento não vai funcionar!

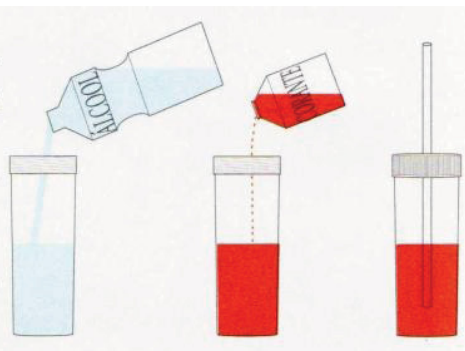

Fig. 3 - Procedimentos 3 e 4 do roteiro de experimentação da situação de aprendizagem 3 do Caderno do Aluno.

Fonte: SÃO PAULO (Estado), 2010, Caderno do Aluno. 


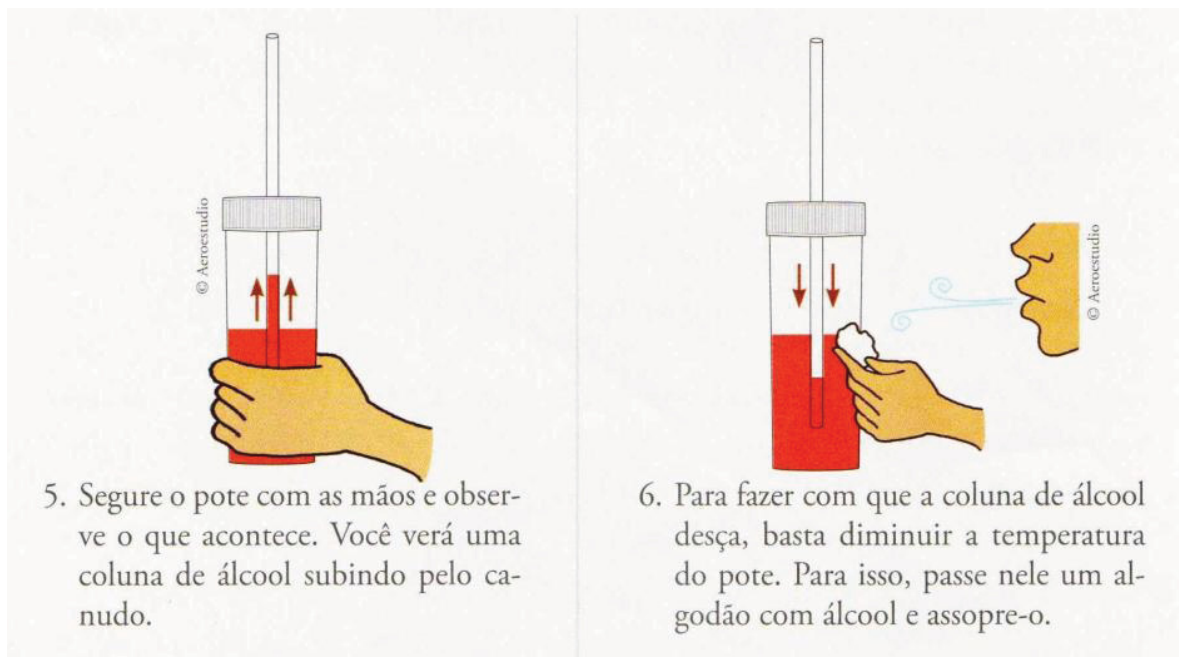

Fig. 4 - Procedimentos 5 e 6 do roteiro de experimentação da situação de aprendizagem 3 do Caderno do Aluno.

Fonte: SÃO PAULO (Estado), 2010, Caderno do Aluno.

\section{Itens 7 e 8}

Nos procedimentos 7 e 8, apresentados na Fig. 5, o roteiro sugere a calibração do termômetro a partir de dois pontos fixos, a fusão do gelo e a temperatura do corpo humano. Ao mergulharmos o termômetro na vasilha com gelo, a coluna de líquido no interior do canudo desce devido à contração térmica sofrida pelo álcool com a queda da temperatura. No entanto, a massa de ar aprisionada no bulbo também sofre uma redução de temperatura e a pressão que este exerce na superfície do líquido se torna menor que a pressão atmosférica sobre a coluna de álcool no interior do canudo. Essa diferença de pressão irá acentuar a descida do líquido pelo canudo de tal forma que, antes mesmo do termômetro entrar em equilíbrio térmico com o gelo fundente, todo o líquido contido no tubo capilar já terá escoado para o bulbo. Logo, não será possível obter o primeiro ponto fixo $\left(\approx 0^{\circ} \mathrm{C}\right)$ da escala, como sugere o roteiro. Para obtenção deste ponto, a posição da coluna líquida no interior do tubo capilar deve estar acima do nível do líquido no bulbo do termômetro. $\mathrm{O}$ quanto acima dependerá principalmente das dimensões do frasco e do canudo, e do líquido utilizado como substância termométrica.

O mesmo problema é observado na obtenção do segundo ponto fixo da escala (temperatura corporal), descrito no procedimento 8. Ao segurarmos o frasco 
com a mão, o líquido se aquece e se expande; fato que é observado pela elevação da coluna de álcool no interior do tubo. Do mesmo modo que ocorre durante o resfriamento, no aquecimento, o ar contido no bulbo também sofre expansão, exercendo uma pressão maior que a atmosférica na superfície do líquido, fazendo com que o líquido suba de maneira mais pronunciada. Esse fato compromete a calibração do segundo ponto fixo, pois o álcool entorna pelo canudo antes do termômetro entrar em equilíbrio térmico com a mão da pessoa. O problema se torna ainda maior se o frasco utilizado como bulbo for totalmente envolvido pela mão da pessoa, como no caso de frascos pequenos sugeridos no roteiro. Alguém poderia até perguntar: e se usássemos tubos mais compridos ou com maior diâmetro? Nesse caso, talvez o problema pudesse ser resolvido, mas o quanto maior deve ser o tubo? Responder a essa e a outras perguntas não é tão complicado; apesar de simples, é necessária uma investigação cuidadosa do problema.

Mesmo que solucionássemos os problemas dos procedimentos 7 e 8 , fazendo com que o líquido se mantivesse no tubo na obtenção dos dois pontos fixos, ainda deveríamos otimizar o processo para que fosse possível construir a escala termométrica na parte externa do frasco, a fim de evitar erros grosseiros de paralaxe. Pela ilustração mostrada no procedimento 9, corre-se o risco de um dos pontos fixos se localizar na direção da tampa do frasco, fazendo com que a precisão deste ponto seja perdida. Portanto, para que o experimento funcione de maneira efetiva é necessário que os dois pontos fixos possam ser obtidos na região do canudo externa ao frasco. Aqui se deve atentar ao comprimento do tubo que teremos disponível nesta região e a altura inicial da coluna líquida antes da calibração.

Outro problema relacionado às ilustrações fora de escala é verificado de maneira exagerada no procedimento 7 , podendo até mesmo induzir a erros conceituais. Na Fig. 5, a primeira ilustração trata do processo de contração do líquido devido a seu resfriamento. Note que há um aumento expressivo do volume do líquido dentro do frasco justificado apenas pela diminuição do líquido contido no tubo, uma vez que a contração do ar dentro do frasco não é considerada. A impressão que essa figura nos passa é que ocorre uma expansão significativa do volume de líquido no interior do frasco devido ao resfriamento do mesmo, o que está absurdamente incorreto. Esse exagero não é observado no caderno do professor.

Quando ocorre o resfriamento ou o aquecimento do sistema, este se contrai ou se dilata como um todo, até mesmo o bulbo, não sendo possível observar mudanças significativas no volume do líquido no interior do frasco. Se for utilizado um frasco grande, como mostram as ilustrações, esse efeito é menos pronunciado ainda, já que a quantidade de líquido contida no tubo é muito pequena em comparação com o volume do frasco. 
A Fig. 6 mostra alguns termômetros montados a partir desse roteiro por grupos de alunos da rede pública de ensino. Note a variedade de tamanhos e materiais de que são compostos os potes. Como comentado anteriormente, no segundo termômetro, da esquerda para direita, foi utilizado um pote de maionese como bulbo, equívoco conduzido pelas ilustrações fora de escala. Nenhum desses termômetros funcionou da maneira esperada e descrita pelo roteiro por problemas de vedação do sistema, pela utilização de colas inadequadas, e calibração para a construção da escala termométrica.

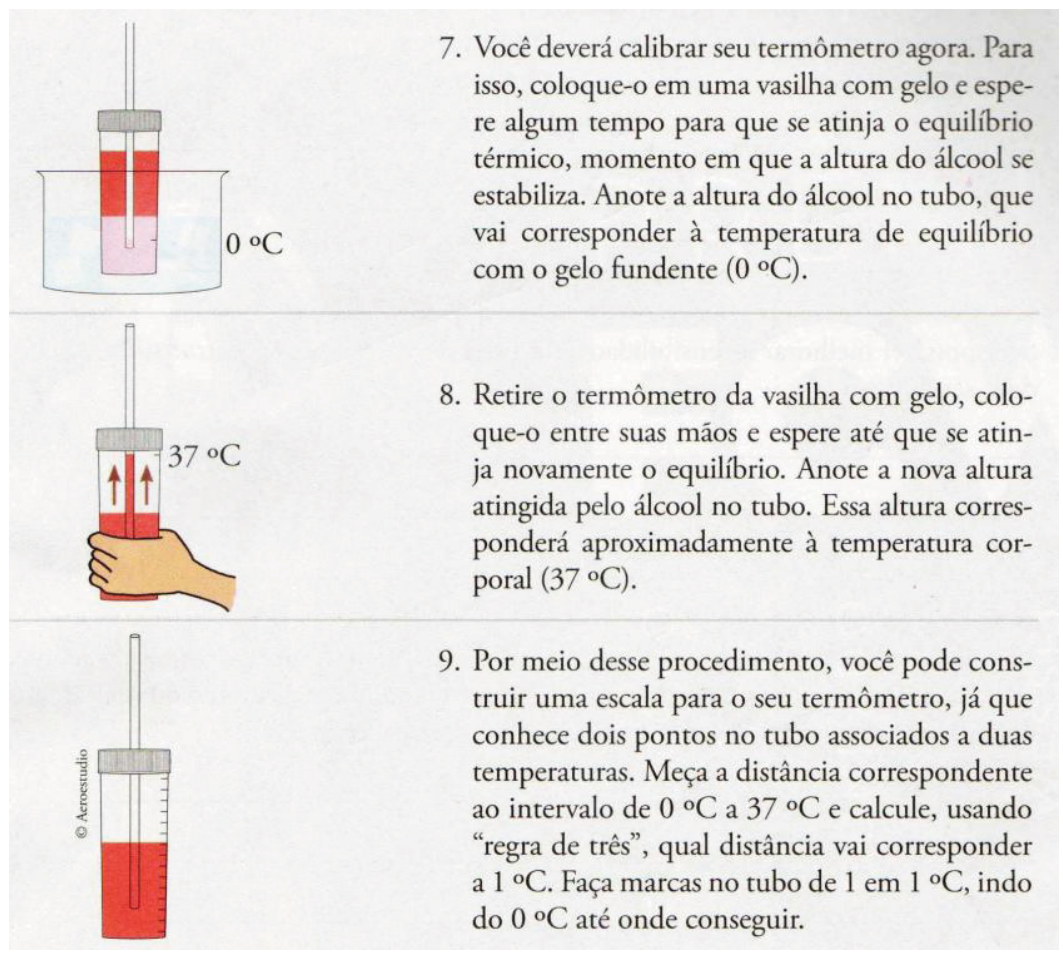

Fig. 5 - Procedimentos 7, 8 e 9 do roteiro de experimentação da situação de aprendizagem 3 do Caderno do Aluno.

Fonte: SÃO PAULO (Estado), 2010, Caderno do Aluno. 

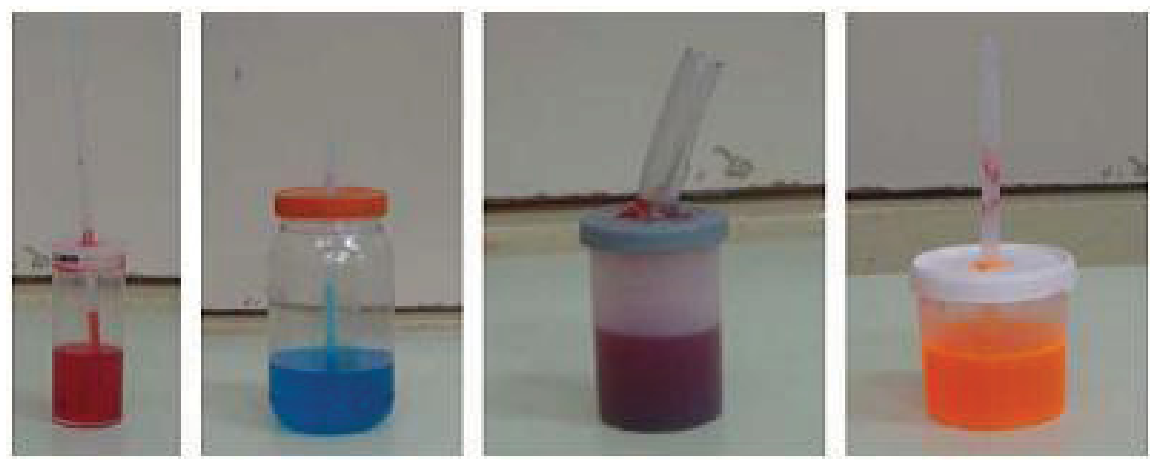

Fig. 6 - Termômetros construídos por grupos de alunos da rede pública de ensino, seguindo os procedimentos descritos pelo roteiro de experimentação da situação de aprendizagem 3 do Caderno do Aluno.

Apesar da nota que aparece após o último procedimento (Fig. 7), o professor ou o aluno que tentarem realizar esse experimento seguindo o roteiro não conseguirá obter o termômetro de coluna líquida, proposto inicialmente. Eles obterão um instrumento parecido com um termoscópio, que é um dispositivo que apenas permitirá a observação do fenômeno da dilatação e contração térmica, ilustrados nos procedimentos 5 e 6 da Fig. 4. Portanto, diante dos diversos erros procedimentais, os professores e alunos geralmente constatam o contrário do que diz a conclusão, ou seja, não é possível construir um termômetro similar aos vendidos no comércio com este roteiro. Infelizmente, o que, em geral, ocorre é a frustração de ambas as partes, professores e alunos, ao relacionarem o não funcionamento do dispositivo a algum erro procedimental cometido por eles mesmos.

É importante salientar que, apesar da simplicidade do experimento, tanto em sua descrição fenomenológica quanto em sua montagem, muitos cuidados devem ser tomados para obtenção do resultado desejado em sala de aula. Na próxima seção, investigamos como os problemas podem ser corrigidos de modo que o termômetro possa ser construído e calibrado para funcionar de maneira similar àqueles encontrados no comércio. 


\section{Pronto!}

Você acaba de construir um termômetro similar aos que são vendidos na farmácia. O funcionamento é o mesmo, o que muda é o material que foi usado para construí-lo.

Fig. 7 - Quadro notificando o término da construção do termômetro sugerido no roteiro de experimentação da situação de aprendizagem 3 do Caderno do Aluno.

Fonte: SÃO PAULO (Estado), 2010, Caderno do Aluno.

\section{Otimizando o processo}

\section{III.1 Componentes de um termômetro de coluna líquida}

Primeiramente, vamos nos atentar para os componentes básicos de um termômetro de coluna líquida os quais são dados pelo bulbo, o tubo capilar, a substância termométrica, a escala termométrica e suas respectivas funções.

O bulbo funciona como um reservatório para o líquido utilizado como substância termométrica. A princípio, qualquer frasco de vidro ou de plástico que seja transparente ou pelo menos translúcido o suficiente para enxergarmos o líquido contido em seu interior poderá ser utilizado. A Fig. 8 mostra algumas opções de frascos que podem ser testados para essa finalidade.

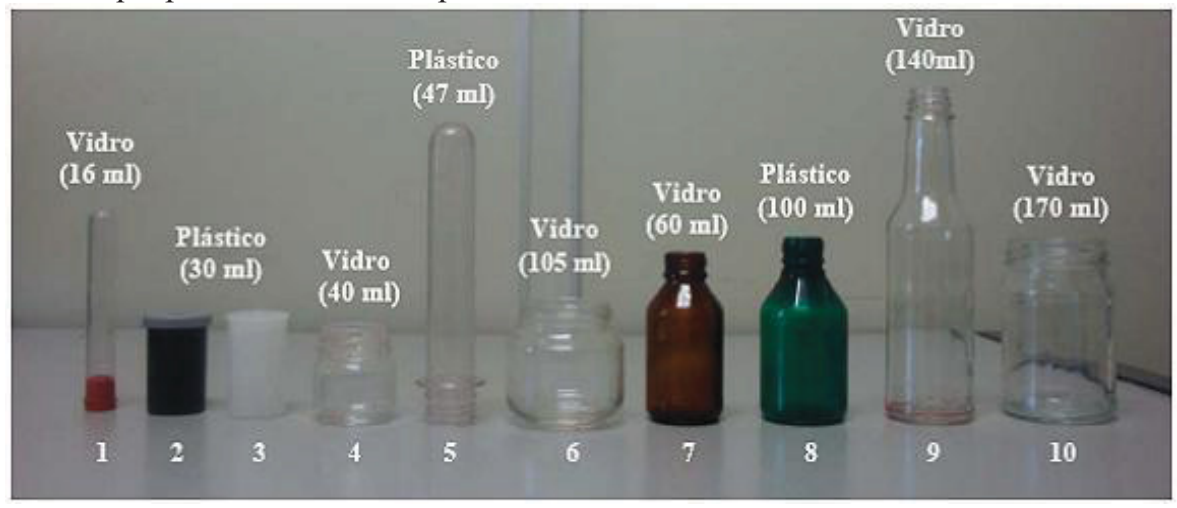

Fig. 8 - Exemplos de recipientes que podem, em princípio, ser utilizados como bulbo do termômetro. 
O tubo capilar será o indicativo de temperatura, com o líquido subindo ou descendo à medida que ocorrem mudanças de temperatura no ambiente ou corpo em que o termômetro estiver em contato. O ideal para a sua construção seria utilizarmos tubos finos de vidro, mas geralmente não são facilmente encontrados no comércio. Uma alternativa interessante é a utilização de tubos de plástico com diâmetro interno entre 2 e $4 \mathrm{~mm}$, como canudos de refresco ou tubinhos de borrifadores de produtos de limpeza ou higiene pessoal, por exemplo. Como no bulbo, é importante que os tubos sejam transparentes ou translúcidos o suficiente para enxergarmos nitidamente a variação da altura da coluna líquida em seu interior. A Fig. 9 mostra algumas sugestões que podem funcionar como tubo capilar.

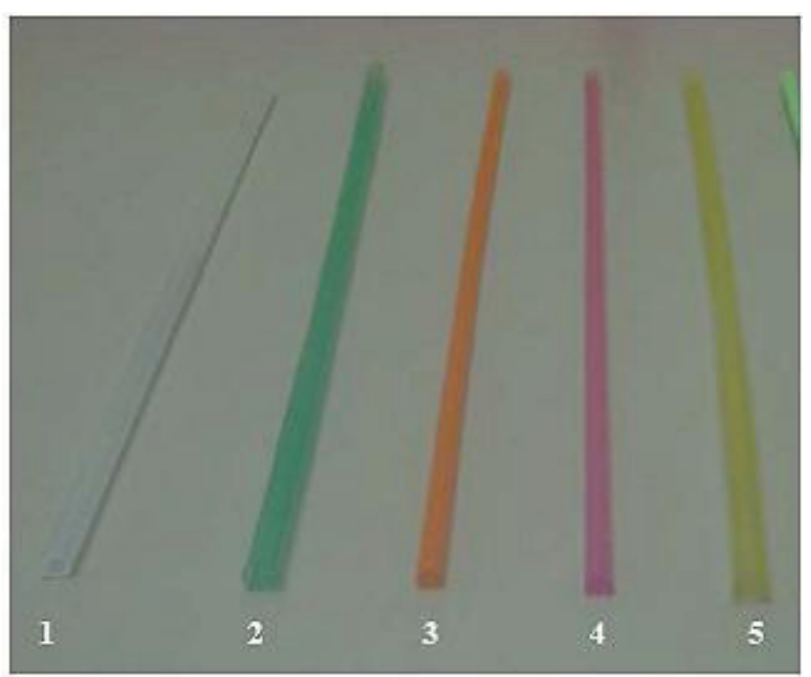

Fig. 9 - Alguns tubos de plástico que, em princípio, podem ser utilizados como tubo capilar para o termômetro.

Para a substância termométrica, temos, inicialmente, duas opções: álcool comum (92,8 $8^{0}$ INPM) e água. Tanto para a primeira quanto para a segunda substância, como são incolores, será necessária a adição de algumas gotas de corante para que a dilatação do líquido no tubo capilar se torne visível.

Para obtenção da escala termométrica, é necessário calibrar o termômetro a partir de dois pontos fixos escolhidos de modo que estes sejam obtidos na região exterior ao bulbo. Para fazer as marcações da escala é recomendável a utilização de uma caneta marcadora de CDs ou DVDs, já que o tubinho é feito de plástico. 
Diante de tantos materiais alternativos para a construção do termômetro, precisamos analisar quais são os mais adequados para a atividade. É necessário verificar qual a melhor combinação - frasco e tubo - em termos de composição (plásticos, vidros, etc) e dimensões e também qual a melhor substância termométrica para obtermos maior precisão e menor tempo de resposta na medida de temperatura de um corpo. Outro ponto importante está relacionado ao comprimento do tubo disponível para desenharmos a escala do termômetro. Este deve ser suficiente para fixarmos pelo menos os dois pontos fixos escolhidos.

Fazer essa análise é muito importante para que o trabalho não seja baseado meramente em tentativas e erros. Além disso, ela também nos mostrará a quantidade de informações que podemos extrair desse simples experimento e o quanto a atividade experimental pode complementar o estudo teórico de determinados fenômenos.

\section{III.2 Analisando cada componente do termômetro durante sua montagem}

Para o bulbo do termômetro, devemos atentar para os seguintes fatores: primeiramente para o material o qual é feito o frasco e em seguida para sua capacidade volumétrica. Para entendermos a importância disso, precisamos observar de que maneira será realizada a medida de temperatura de um corpo.

Esta será obtida pelo contato direto com o bulbo do termômetro. Portanto, teremos transmissão de calor por condução do corpo para as paredes do bulbo. Logo, se o material que compõe o bulbo for um material de alta condutividade térmica, teremos menor tempo de resposta para a medida de temperatura, ou seja, o sistema corpo e paredes do bulbo entrarão em equilíbrio térmico mais rapidamente. Isso é muito útil para não perdermos tempo durante a calibração do termômetro, o que poderia tornar a atividade cansativa e desinteressante, sem contar que ainda teremos o processo de obtenção de equilíbrio térmico entre as paredes do bulbo e a substância termométrica, que discutiremos a seguir. A tabela I mostra a condutividade térmica de alguns materiais à temperatura ambiente $\left(25^{\circ} \mathrm{C}\right)$. Note que o vidro apresenta uma condutividade térmica de 30 até 130 vezes maior que os plásticos, sendo, por isso, a melhor alternativa para o material do bulbo. 
TABELA I: Condutividade térmica de alguns materiais à temperatura ambiente $\left(\sim 25^{\circ} \mathrm{C}\right)$ (GASPAR, 2000; FRADE e PAIVA, 2006).

\begin{tabular}{|l|l|}
\hline Materiais & Condutividade térmica $\left(\mathbf{W} / \mathbf{m}^{\circ} \mathbf{C}\right)$ \\
\hline Vidro & 0,8 \\
\hline Polietileno & $\approx 0,027$ \\
\hline Poliestireno & 0,006 a 0,013 \\
\hline
\end{tabular}

A capacidade volumétrica do bulbo será importante tanto para a obtenção de equilíbrio térmico com maior rapidez quanto para a construção da escala. No primeiro caso, é fácil entendermos, pois se tentarmos aquecer a quantidade de um balde cheio de água até a temperatura de ebulição, veremos que o tempo necessário para atingir essa temperatura será bem maior que aquele necessário para a quantidade de um copo com água. O processo de aquecimento, nesse caso, ocorre não só pela transmissão de calor por condução, mas também por convecção, que ocorre quando um fluido, como o ar (gás) ou um líquido, está em contato com um objeto cuja temperatura é maior ou menor que a deste, como as paredes do bulbo. Portanto, quanto menor a quantidade de líquido, menor será o tempo para que o sistema entre em equilíbrio. No segundo caso, utilizaremos o ferramental matemático para descobrir qual o volume máximo que podemos considerar para um comprimento fixo do tubo capilar, no intuito de viabilizar a construção da escala termométrica. Note que não temos muitas opções referentes ao comprimento dos tubos, mas temos muitas referentes à capacidade dos frascos. Por isso, dizemos que o comprimento do tubo é fixo.

Já que estamos tentando reproduzir o funcionamento de um termômetro de coluna líquida comercial, a hipótese inicial será a de que preencheremos completamente o volume do bulbo e parte do tubo capilar com a substância termométrica. Se utilizarmos um canudinho, por exemplo, como tubo capilar, obteremos um comprimento fixo de aproximadamente $25 \mathrm{~cm}$. É importante lembrarmos que teremos que introduzir parte do canudo dentro do bulbo, ficando assim com um comprimento ainda menor para fazermos a escala do termômetro, dado por $h$, como ilustra a Fig. 10.

Para obtenção do volume mais adequado do bulbo, vamos tomar $\mathrm{h}=20 \mathrm{~cm}$ e utilizar a equação que descreve a dilatação volumétrica de um material, dizendo que, se a temperatura de um sólido ou de um líquido, cujo volume inicial é $V_{0}$, aumentar de $\Delta T$ sua variação de volume é dada por:

$$
\Delta V=V_{0} \cdot \gamma \cdot \Delta T
$$




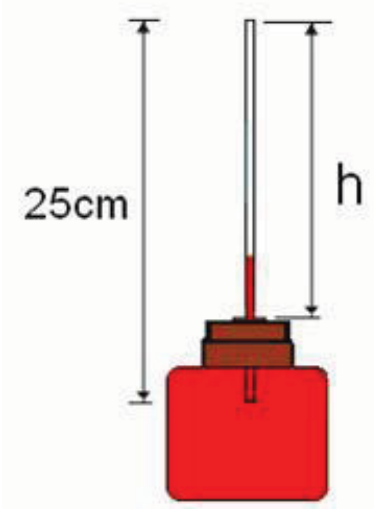

Fig. 10 - Protótipo do termômetro para otimização do volume do bulbo para o comprimento de um canudo de $25 \mathrm{~cm}$. O valor de hé o comprimento disponivel para a construção da escala termométrica. Na figura, a substância termométrica é representada em cor vermelha.

sendo $\Delta V$ o volume do líquido dilatado, $V_{0}$ o volume inicial do líquido, $\gamma$ o coeficiente de dilatação volumétrica da substância termométrica e $\Delta T=T-T_{0}$ a variação de temperatura sofrida pelo líquido. Para os líquidos, a expansão volumétrica é o único parâmetro de expansão que faz algum sentido, pois o mesmo toma a forma do recipiente que o contém. Vamos obter o valor de $V_{0}$ para um $\Delta V$ correspondente $\mathrm{a} \mathrm{h}=18 \mathrm{~cm}$. Poderia surgir a pergunta: mas o valor de $h$ não foi considerado como sendo de $20 \mathrm{~cm}$ ? Sabemos que sim, mas vamos deixar $2 \mathrm{~cm}, 1 \mathrm{~cm}$ acima e $1 \mathrm{~cm}$ abaixo das extremidades de $h$ para não termos o problema de ficarmos restritos exatamente às fronteiras do canudo, evitando derramamento de líquido durante um aquecimento, ou perda da visibilidade do líquido no canudo durante um resfriamento. Se tomarmos um canudo com diâmetro de $0,3 \mathrm{~cm}$, seu volume para $h=18 \mathrm{~cm}$ é dado por:

$$
\Delta V=A \cdot h=\pi \cdot r^{2} \cdot h \approx 1,27 \mathrm{ml},
$$

sendo $A$ sua área circular. Note que temos $r=0,15 \mathrm{~cm}$ e a conversão de unidade é dada por $1 \mathrm{~cm}^{3}=1 \mathrm{ml}$. Manipulando a eq. (1) temos:

$$
V_{0}=\frac{\Delta V}{\gamma \cdot \Delta T} \text {. }
$$


A equação acima nos diz qual será o volume inicial de líquido $\left(V_{0}\right)$ para uma dilatação máxima dada pelo volume do tubo disponível $(\Delta V)$ para construirmos a escala termométrica no intervalo de temperatura $\Delta T$ utilizando uma substância termométrica $\gamma$. Note que ainda precisamos definir os dois últimos parâmetros. Para uma análise preliminar, vamos tomar por conveniência o álcool etílico $\left(92,8^{0}\right.$ INPM) como substância termométrica, cujo coeficiente de dilatação volumétrica é dado por $\gamma=1,1 \times 10^{-3 o} C^{-1}$ e por ser a sugestão dada pelo roteiro experimental do Caderno de Física. Mais adiante mostraremos as vantagens de trabalharmos com álcool em vez de água, por exemplo. Vamos tomar o $\Delta T$ como sendo a diferença de temperatura entre os dois pontos fixos que utilizaremos, ou seja, o gelo fundente $\left(T_{g} \sim 0{ }^{\circ} \mathrm{C}\right)$ e a temperatura corporal $\left(T_{C} \sim 37^{\circ} \mathrm{C}\right)$. Logo, temos que $\Delta T=T_{C}-T_{g}=$ $37^{\circ} \mathrm{C}$. Substituindo todos os valores na eq. (3) calculamos o valor de $V_{0} \approx 31 \mathrm{ml}$.

Obtemos, então, o volume máximo do bulbo para que possamos construir uma escala termométrica para observar uma variação de temperatura de $37^{\circ} \mathrm{C}$. Segundo nossa análise, a temperatura de $0^{\circ} \mathrm{C}$ estará aproximadamente a $1 \mathrm{~cm}$ acima da tampa do frasco de $V_{0} \approx 31 \mathrm{ml}$ e a de $37^{\circ} \mathrm{C}$ a $1 \mathrm{~cm}$ abaixo da extremidade superior do canudo. Agora surge outra pergunta: quando o termômetro for construído, o sistema estará à temperatura ambiente, então qual deve ser a altura inicial da coluna líquida no canudo para a obtenção do intervalo de $37^{\circ} \mathrm{C}$ no intervalo de comprimento de $18 \mathrm{~cm}$ ? A resposta é simples. Primeiramente, devemos nos lembrar de que estamos fazendo uma estimativa e não um cálculo totalmente exato das posições desses pontos no canudo. Isso justifica o motivo de termos descontado $2 \mathrm{~cm}$ em $h$ para possíveis desvios dos cálculos, uma vez que as temperaturas $T_{g}, T_{C}$ e a ambiente podem não ser exatamente as consideradas. Supondo que a temperatura ambiente seja de $T_{A}=25^{\circ} \mathrm{C}$, para resfriar o sistema a $0^{\circ} \mathrm{C}$ temos um $\Delta T_{1}=T_{A}-T_{g}$ $=25^{\circ} \mathrm{C}$. Analogamente, para aquecermos o sistema a $37^{\circ} \mathrm{C}$, temos $\Delta T_{2}=37-25=$ $12^{\circ} \mathrm{C}$, de modo que $\Delta T_{1}+\Delta T_{2}=37^{\circ} \mathrm{C}$, que é nosso $\Delta T$ total. Se partirmos da temperatura ambiente, teremos então que resfriar o sistema em $68 \%$ do nosso $\Delta T$ total e aquecê-lo em $32 \%$ desse mesmo valor. Observe pela eq. (1) que $\Delta V$ é proporcional a $\Delta T$. Pela eq. (2) vemos também que $\Delta V$ é proporcional a $h$, de modo que $h$ torna-se diretamente proporcional a $\Delta T$. Portanto, podemos tomar a correspondência entre a variação de $h$ no termômetro e a temperatura $T$ equivalente, como sendo uma função linear, ou seja,

$$
T(h)=a \cdot h
$$

sendo a uma constante que dependerá do líquido utilizado no termômetro. Para a construção da escala, podemos dividir o valor total de $h$ disponível na mesma proporção, já que para cada valor de $h$ temos uma temperatura $T$ linearmente corres- 
pondente. Essa aproximação é a mais simples que podemos fazer e veremos que é razoável. Logo, considerando que estamos partindo da temperatura ambiente, temos, para a altura inicial da coluna líquida, $\mathrm{h}_{0}=68 \% \times 18 \mathrm{~cm}+1 \mathrm{~cm} \approx 13,2 \mathrm{~cm}$. Somamos $1 \mathrm{~cm}$ para medirmos $\mathrm{h}_{0}$ a partir da tampa do frasco. Lembre-se de que descontamos $1 \mathrm{~cm}$ acima e $1 \mathrm{~cm}$ abaixo no canudo. Esse procedimento será utilizado para a calibração do termômetro nos dois pontos fixos escolhidos e é ilustrado na Fig. 11.a, mostrando a coluna em $\mathrm{h}_{0}$ (posição inicial) e as possíveis posições de $T_{C}$ e $T_{g}$. A Fig. 11.b ilustra o termômetro calibrado e com a escala termométrica pronta.

Dos frascos apresentados na Fig. 8 vemos que, para um termômetro construído com um canudo de $25 \mathrm{~cm}$ de comprimento e $0,3 \mathrm{~cm}$ de diâmetro, poderíamos utilizar os frascos 1, 2 ou 3. Porém, o frasco 1 (tubo de ensaio ${ }^{1}$ ) seria o mais adequado por ser de vidro, por razões já esclarecidas anteriormente. O tubo de ensaio tem a vantagem de possuir paredes bem finas e uniformes e ser um tubo estreito, o que pode contribuir muito no processo de obtenção de equilíbrio térmico com maior rapidez.

Vamos agora analisar a substância termométrica. O álcool e a água são dois líquidos de fácil acesso para trabalharmos. Devemos atentar para a finalidade dessa substância no funcionamento do termômetro para sabermos qual delas será a melhor. Já vimos que o líquido irá subir ou descer no tubo, conforme variamos a temperatura do corpo que é colocado em contato com o termômetro. Portanto, a substância termométrica deve dilatar o suficiente para observarmos variações de temperatura no $\Delta T$ escolhido. Em nossa análise, esse intervalo de temperatura é de aproximadamente $37^{\circ} \mathrm{C}$ em um intervalo de comprimento de $18 \mathrm{~cm}$. É um $\Delta T$ relativamente pequeno, se compararmos com um termômetro de mercúrio comercial simples, o qual nos permite verificar temperaturas de até $150^{\circ} \mathrm{C}$, com precisão de $1{ }^{\circ} \mathrm{C}$, em um intervalo de comprimento de 13 a $14 \mathrm{~cm}$. O coeficiente de dilatação volumétrica do mercúrio é de $\gamma_{M}=1,8 \times 10^{-4}{ }^{\circ} \mathrm{C}^{-1}$, enquanto que o do álcool é de $\gamma_{A}=11 \times 10^{-4}{ }^{\circ} \mathrm{C}^{-1}$, ou seja, $\gamma_{A}=6,1 \gamma_{M}$. Para o coeficiente de dilatação volumétrica da água, temos alguns valores para diferentes intervalos de temperatura na tabela II.

\footnotetext{
${ }^{1}$ Esse tubo de ensaio é utilizado na coleta de sangue ou para armazenar agulhas utilizadas em acupuntura. Ele pode ser facilmente adquirido em postos de saúde, laboratórios de análises clínicas ou em clínicas de acupuntura.
} 


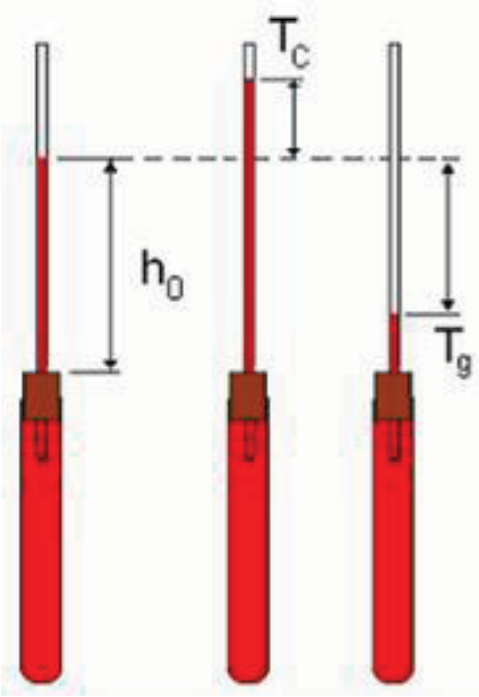

(a)

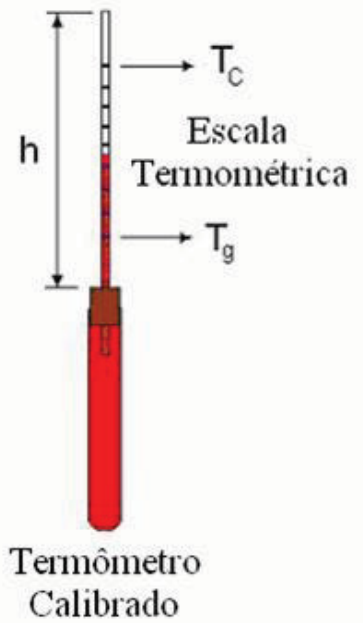

(b)

Fig. 11 - (a) Ilustração do termômetro mostrando a altura inicial $h_{0}$ e a posição dos pontos fixos $T_{C}$ e $T_{g}$ durante a calibração. (b) Termômetro calibrado e com a escala termométrica.

Para as condições deste experimento, quanto maior o valor de $\gamma$ melhor, pois os tubos disponíveis para a construção do tubo capilar proposto no roteiro possuem diâmetros em torno de 2 e $4 \mathrm{~mm}$. Para termos noção de comparação, o tubo capilar de um termômetro comercial possui aproximadamente $0,5 \mathrm{~mm}$ de diâmetro, ou seja, é 4 a 8 vezes menor. O diâmetro do tubo capilar influencia na precisão do termômetro. Se este for menor, podemos observar variações volumétricas menores, veja eq. (2), o que implicaria a possibilidade de leitura de pequenas variações de temperatura. Logo, para aumentar a precisão do termômetro, basta conseguir um tubo capilar com diâmetro menor. É claro que devemos nos atentar ao comprimento disponível para a construção da escala, necessitando fazer os cálculos das eq. (2) e (3) para os novos parâmetros para que o termômetro possa ser calibrado adequadamente. Portanto, não há dúvidas de que o álcool é realmente a melhor opção, pois possui um coeficiente de dilatação volumétrica mais de seis vezes maior que o do mercúrio, comumente utilizado para esses fins, e até vinte e uma vezes maior que os valores de $\gamma_{\text {Água }}$ para a água no intervalo de temperatura escolhido, de 0 a $37^{\circ} \mathrm{C}$. 
É interessante observarmos a grande variação de $\gamma_{\text {Água, }}$ tabela II, em pequenos intervalos de temperatura. No intervalo de temperatura que trabalharemos, de 0 a $37^{\circ} \mathrm{C}$, o valor de $\gamma_{\text {Agua }}$ pode variar em mais de $600 \%$, tornando, obviamente, inviável sua utilização como substância termométrica. A Fig. 12.a mostra a variação de volume em função da temperatura para o álcool e a glicerina para temperaturas acima de $25^{\circ} \mathrm{C}$. Note que, para as duas substâncias, temos um comportamento linear, em boa aproximação. Isso mostra que a consideração na eq. (4) é válida para o álcool. O comportamento da dilatação volumétrica da glicerina em função da temperatura foi colocado para mostrar que outras substâncias podem também dilatar linearmente, em determinados intervalos de temperatura, como o álcool. $\mathrm{Na}$ Fig. 12.b temos o mesmo gráfico para a água mostrando, pelo ajuste linear, um comportamento não linear. Portanto, a aproximação dada pela eq. (4) não é viável para a água. Observe no gráfico inserido na Fig. 12.b que, para o intervalo entre $0 \mathrm{a}$ $10^{\circ} \mathrm{C}$, a água tem um comportamento mais distante ainda do linear, caracterizado por um aumento no volume com a diminuição da temperatura, o que significa que sua densidade (inverso do volume) passa por um máximo $\left(\sim 4^{\circ} \mathrm{C}\right)$. É interessante notar que o mais comum dos líquidos, a água, não se comporta como os outros líquidos. Este é o chamado comportamento anômalo da água. Nessa discussão, o professor poderia aproveitar para explicar porque os lagos ou os pequenos cubos de gelo formados no congelador congelam primeiro na superfície e a importância desse fenômeno para a existência de toda a vida aquática nas regiões de invernos rigorosos. Esse é mais um argumento para reforçar que a melhor opção para a substância termométrica do termômetro é o álcool.

Na próxima seção são apresentados alguns resultados obtidos a partir das análises realizadas até o momento.

TABELA II: Coeficientes de dilatação térmica da água para alguns intervalos de temperatura (PIMENTEL, 2000).

\begin{tabular}{|c|c|}
\hline Intervalo de temperatura $\left({ }^{\circ} \mathbf{C}\right)$ & $\gamma_{\text {Água }}\left(\mathbf{1 0}^{-4}{ }^{\mathbf{}} \mathbf{C}^{-\mathbf{1}}\right)$ \\
\hline $5-10$ & 0,53 \\
\hline $10-20$ & 1,50 \\
\hline $20-40$ & 3,00 \\
\hline $40-60$ & 4,60 \\
\hline
\end{tabular}



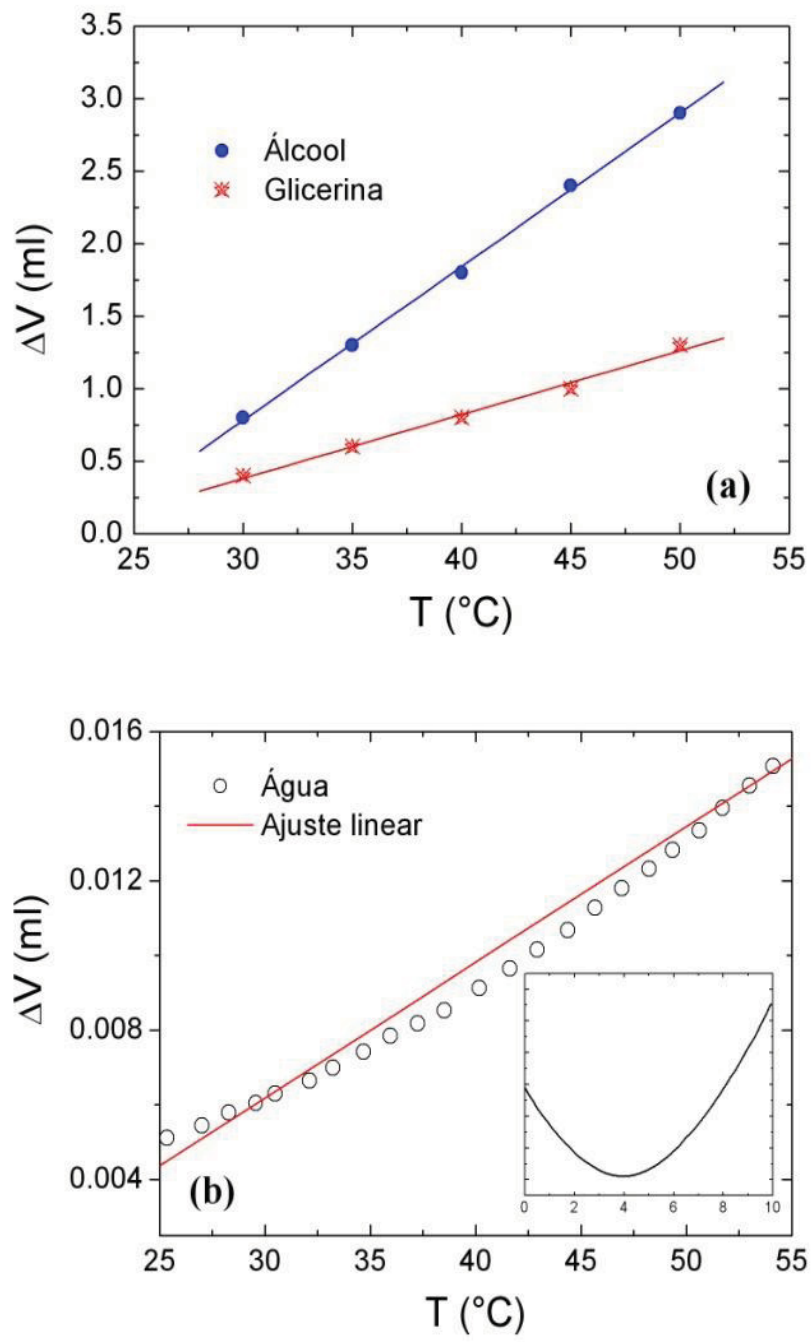

Fig. 12 - (a) Dilatação volumétrica do álcool e da glicerina para temperaturas acima de $25^{\circ} \mathrm{C}$, mostrando um comportamento linear (NETTO, 2010). (b) Comportamento não-linear da dilatação volumétrica da água para o mesmo intervalo de temperatura. $O$ gráfico inserido mostra a dilatação volumétrica entre 0 e $10^{\circ} \mathrm{C}$ (HALLIDAY; RESNICK; WALKER, 1993). 


\section{III.3 Montagem do Termômetro e Testes}

\section{Montagem}

Para testar o funcionamento do termômetro, primeiramente utilizamos os parâmetros descritos na seção anterior, ou seja, o tubo de ensaio (tubo 1 - Fig. 8) de volume $\mathrm{V}_{0}=16 \mathrm{ml}$, um canudo de refresco com diâmetro de $0,3 \mathrm{~cm}$ e $25 \mathrm{~cm}$ de comprimento e álcool etílico $\left(92,8^{0}\right.$ INPM) como substância termométrica. Os pontos fixos escolhidos foram o ponto de gelo $\left(\mathrm{T}_{\mathrm{g}}=0^{\circ} \mathrm{C}\right)$ e a temperatura corporal, em torno de $37^{\circ} \mathrm{C}$, ou seja, $\Delta T=37^{\circ} \mathrm{C}$.

Os detalhes da montagem são descritos pelas etapas abaixo:

1. Primeiro é necessário furar a tampa do tubo de ensaio, a qual pode ser de borracha ou plástico, com uma broca preferencialmente com o mesmo diâmetro externo do canudo (tubo capilar).

2. Para facilitar a introdução do canudo na tampa, podemos fazer um corte diagonal à secção transversal do mesmo, como mostra a Fig. 13. As dimensões são as mesmas descritas na seção anterior, disponibilizando $20 \mathrm{~cm}$ acima da tampa, para a construção da escala, e $5 \mathrm{~cm}$ abaixo.

3. Para evitar possíveis vazamentos na junção do canudo com a tampa, é necessário fazer uma vedação com cola. Dê preferência à cola epóxi (Araldite 10 minutos), pois cola branca não adere à superfície plástica do canudo, podendo comprometer o experimento. Apesar de eficiente, evite o uso de cola quente, pois esta pode causar sérias queimaduras se não for manipulada com cuidado. Outra vantagem da cola epóxi é a secagem rápida. Essa vedação é fundamental para o funcionamento do termômetro, pois qualquer vazamento impedirá a sustentação da coluna de líquido acima da tampa do reservatório (bulbo).

4. Finalmente, preenchemos o bulbo com a substância termométrica, lembrando que é necessário adicionar corante ao álcool para torná-lo mais visível, e introduzimos o conjunto tampa-canudo para vedar o bulbo. Se a tampa do tubo de ensaio for de borracha, não haverá problemas quanto à vedação do conjunto, pois a borracha é encaixada de maneira bem justa, mas se for de plástico será necessário utilizar a cola epóxi na junção. Caso for escolhido um frasco que tenha tampa com rosca, a vedação pode ser feita com teflon, utilizado para fazer encanamentos. Para confirmar se as junções descritas estão efetivamente vedadas, é só observar que a coluna líquida que sobressai a tampa do tubo, no momento em que a encaixamos, mantém-se a uma altura constante. Se isso não acontecer, observaremos a precipitação do líquido em uma das duas junções, decorrente do escoamento do líquido do canudo, sendo necessário rever a vedação. 


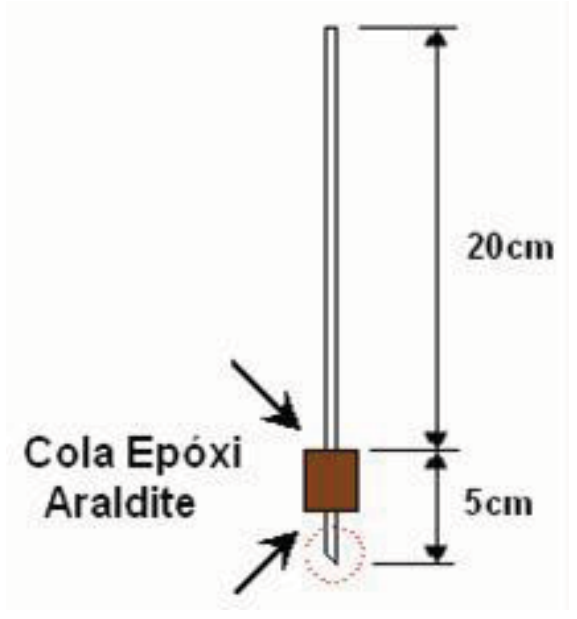

Fig. 13 - Esquema da montagem do canudo na tampa do tubo de ensaio (bulbo). O círculo pontilhado mostra o corte diagonal à secção transversal na extremidade inferior do canudo para facilitar a introdução na tampa do bulbo.

\section{Calibração}

Para iniciarmos o processo de calibração do termômetro, precisamos deixar a coluna líquida a uma altura inicial $\mathrm{h}_{0}$, a qual utilizaremos por comodidade o valor obtido na seção anterior para $V_{0}=31 \mathrm{ml}$, ou seja, $\mathrm{h}_{0}=68 \% \times 18 \mathrm{~cm}+1 \mathrm{~cm} \approx$ $13,2 \mathrm{~cm}$.

Agora poderia surgir a pergunta: Se o volume do frasco utilizado é de $\mathrm{V}_{0}=16 \mathrm{ml}\left(52 \%\right.$ de $\left.\mathrm{V}_{0}=31 \mathrm{ml}\right)$, porque não utilizar um $\mathrm{h}_{0}$ equivalente para este volume, ou seja, $52 \%$ x $13,2 \mathrm{~cm}=6,9 \mathrm{~cm}$ ? Utilizamos o valor inicial de $\mathrm{h}_{0}$ porque este foi calculado para um $V_{0}$ máximo, portanto, não haverá problemas se utilizarmos esse mesmo valor para volumes iniciais menores. Se não for atingida uma altura inicial próxima de $\mathrm{h}_{0}$ quando a tampa do tubo for colocada, pode-se completar a coluna líquida com uma seringa ou qualquer outro instrumento. Para o álcool esse procedimento é bem simples, já que este líquido não possui tanta tensão superficial como a água. A Fig. 14 mostra o termômetro pronto com a coluna líquida inicial em $\mathrm{h}_{0}$.

É muito importante ficar claro que, para cada conjunto de parâmetros, $\Delta V$, $\Delta T$ e $\gamma$, é necessário refazer os cálculos para obtenção de $V_{0}$ e $h_{0}$. 


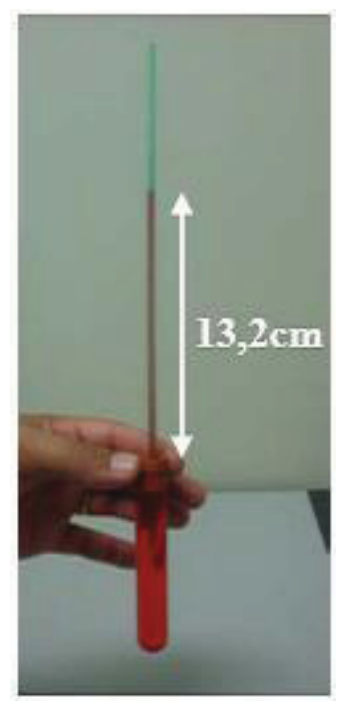

Fig. 14 - Termômetro pronto com a coluna líquida (álcool) inicialmente na posição $h_{0}=13,2 \mathrm{~cm}$.

Para o primeiro ponto fixo $\left(T_{g}=0{ }^{\circ} \mathrm{C}\right)$ tomamos um copo com gelo picado para melhorar o contato com o termômetro. A estabilização da coluna líquida no canudo ocorreu em torno de 15 minutos. Com o equilíbrio térmico atingido, fizemos uma marcação neste ponto com uma caneta marcadora. A temperatura nessa posição foi aferida em $3{ }^{\circ} \mathrm{C}$ com um termômetro comercial, veja Fig. 15 .

Para a determinação do segundo ponto fixo $\left(T_{C}=37^{\circ} \mathrm{C}\right)$, envolvemos o termômetro com a mão. $\mathrm{O}$ equilíbrio térmico foi obtido em aproximadamente 15 minutos, como no primeiro ponto, fato verificado pela estabilização da coluna líquida no canudo. Também foi feita uma marcação no canudo para esse ponto. Em seguida, aferimos, com um termômetro comercial, a temperatura da mão da pessoa que envolveu o termômetro, fornecendo-nos $34^{\circ} \mathrm{C}^{2}$.

\footnotetext{
${ }^{2}$ A temperatura corporal do ser humano está entre 36 e $37^{\circ} \mathrm{C}$. O valor obtido para a temperatura da mão da pessoa que envolveu o termômetro comercial foi de $34{ }^{\circ} \mathrm{C}$. Esse valor menor se deve, provavelmente, ao fato do termômetro ter ficado imerso em gelo fundente por cerca de 15 minutos, imediatamente antes da pessoa segurá-lo. É interessante, mas não necessariamente obrigatório, esperar o termômetro estabilizar a temperatura ambiente antes da obtenção do $2^{\circ}$ ponto fixo.
} 


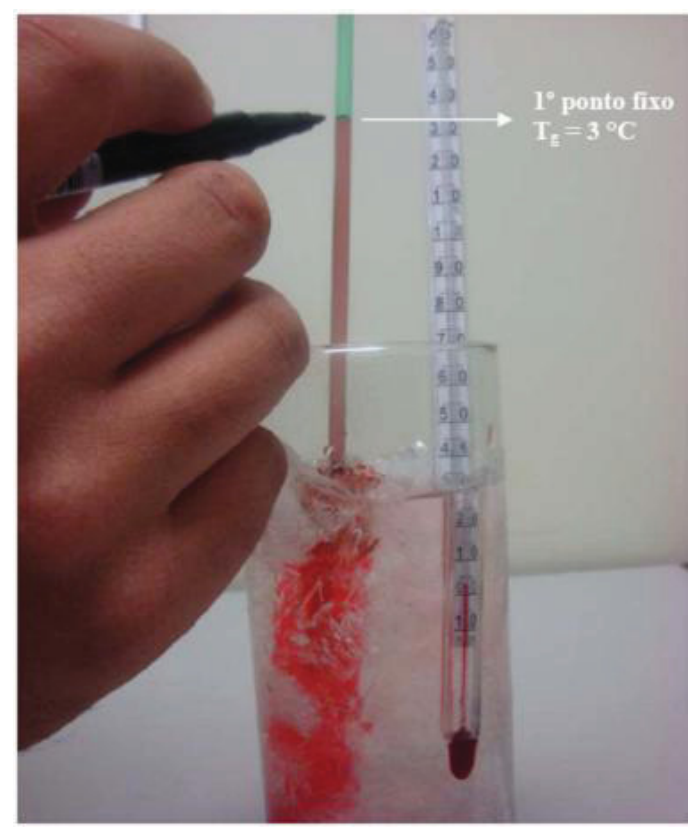

Fig. 15 - Termômetro em equilíbrio térmico com gelo fundente correspondente ao $1^{\circ}$ ponto fixo da escala termométrica $T_{g}=3{ }^{\circ} \mathrm{C}$.

A Fig. 16 mostra a obtenção do $2^{\circ}$ ponto fixo. Note a importância da aferição da temperatura dos dois pontos com um termômetro comercial. Em $T_{g}$ obtemos $3^{\circ} \mathrm{C}$ em vez de $0^{\circ} \mathrm{C}$ e em $T_{C}$ obtemos $34^{\circ} \mathrm{C}$ em vez de $37^{\circ} \mathrm{C}$. Essas diferenças se devem às condições em que o experimento foi realizado. Claro que poderíamos tomar os valores de $0^{\circ} \mathrm{C}$ e $37^{\circ} \mathrm{C}$ como uma aproximação dos pontos fixos sem a aferição do termômetro comercial, mas devemos estar cientes de que estamos fazendo uma aproximação com um erro de até $3^{\circ} \mathrm{C}$, como verificamos. $\mathrm{Na}$ seção anterior já havíamos comentado que os valores dessas temperaturas não seriam exatamente iguais às utilizadas nos cálculos.

Pelos valores obtidos, a variação de temperatura entre os dois pontos fixos é dada por $\Delta T=T_{C}-T_{g}=34-3=31^{\circ} \mathrm{C}$ em um comprimento de $5,9 \mathrm{~cm}$. Pela eq. (4), obtemos para a constante de proporcionalidade $a \approx 5,3^{\circ} \mathrm{C} / \mathrm{cm}$, ou seja, cada centímetro do tubo capilar (canudo) corresponde a $5,3{ }^{\circ} \mathrm{C}$ de temperatura. Se subdividirmos o tubo capilar em intervalos de comprimento de 2 em $2 \mathrm{~mm}$, cada subdivisão corresponderia aproximadamente a $1,06^{\circ} \mathrm{C}$. É importante salientar que não 
podemos utilizar esta calibração em grandes intervalos de tempo, de um dia para o outro, por exemplo, pois ocorre a evaporação do álcool contido no tubo, diferentemente dos termômetros comerciais, onde temos um tubo hermeticamente fechado.

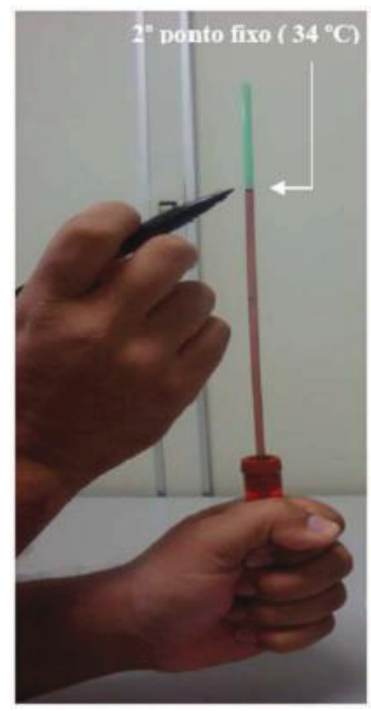

Fig. 16 - Termômetro em equilíbrio térmico com a mão. Obtenção do $2^{\circ}$ ponto fixo da escala termométrica, $T_{C}=34^{\circ} \mathrm{C}$.

Para testar a precisão do termômetro, fizemos a medida da temperatura ambiente onde o experimento foi realizado. A calibração foi feita com a sala climatizada em $T_{A}=22^{\circ} \mathrm{C}$. O comprimento do primeiro ponto fixo ao ponto marcado para a temperatura ambiente foi de $\mathrm{h}=3,8 \mathrm{~cm}$, como mostra a Fig. 17. Pela eq. (4), utilizando o valor de $a$ obtido, temos $\mathrm{T}=5,3^{\circ} \mathrm{C} / \mathrm{cm} \times 3,8 \mathrm{~cm}=20,14^{\circ} \mathrm{C}$, ou seja, $\mathrm{T} \approx 20,1{ }^{\circ} \mathrm{C}$, apresentando mais de $90 \%$ de concordância com a temperatura medida $\left(22^{\circ} \mathrm{C}\right)$.

Poderia agora surgir a seguinte curiosidade: sabendo que a eq. (1) também é válida para sólidos, obteríamos uma temperatura exatamente igual à obtida pelo termômetro comercial se considerássemos a dilatação do bulbo? Não podemos dizer que seria exatamente igual, devido aos diferentes parâmetros dos dois termômetros, mas podemos estimar o erro na medida de temperatura do nosso termômetro pelo cálculo da dilatação volumétrica do bulbo para a variação de temperatura entre os dois pontos fixos, ou seja, $\Delta T=31^{\circ} \mathrm{C}$. Como utilizamos um frasco 
de vidro, faremos uso do coeficiente de dilatação volumétrica deste material, o qual é dado por $\gamma_{V i d r o}=0,27 \cdot 10^{-4 \mathrm{o}} \mathrm{C}^{-1}$. Sendo $V_{0}=16 \mathrm{ml}$, pela eq. (1) obtemos para a variação de volume $\Delta V \approx 0,013 \mathrm{ml}$. Vemos que é uma variação de apenas $0,08 \%$ no volume total do bulbo, mas devemos verificar a influência dessa variação no volume do líquido presente no tubo capilar (canudo), ou seja, o quanto essa variação pode modificar a altura da coluna líquida. No intervalo de temperatura descrito houve uma variação na coluna líquida correspondente a $5,9 \mathrm{~cm}$ do comprimento do canudo, o que nos fornece $V=\pi \times(0,15)^{2}$ x $5,9=0,417 \mathrm{ml}$. Então, o erro pode ser dado por uma simples regra de três, ou seja,

$$
T_{\text {Erro }}=\frac{0,013 m l}{0,417 m l} \times 100 \% \approx 3,1 \% .
$$

Portanto, o erro devido à dilatação do bulbo em um intervalo de $31^{\circ} \mathrm{C}$ está em torno de $3 \%$, ou seja, $\Delta T_{\text {Erro }}=0,93^{\circ} \mathrm{C} \approx 1{ }^{\circ} \mathrm{C}$. Logo, a medida da temperatura ambiente pelo nosso termômetro é dada por $\mathrm{T}=(20 \pm 1)^{\circ} \mathrm{C}$. Note que estamos levando em conta apenas o erro de temperatura referente à dilatação do tubo. Se somarmos todos os erros do experimento, tais como, o erro na aferição de temperatura dos dois pontos fixos e o erro dado pela medida do comprimento (régua) da variação na coluna líquida correspondente, obteríamos um erro maior.

Se tomássemos $T_{g}=0^{\circ} \mathrm{C}$ e $T_{C}=37^{\circ} \mathrm{C}$ sem a aferição do termômetro comercial, obteríamos $T_{A}=6,3^{\circ} \mathrm{C} / \mathrm{cm} \times 3,8 \mathrm{~cm}=23,9^{\circ} \mathrm{C}$ para a temperatura ambiente, ou seja, uma temperatura superestimada já que $\mathrm{T}=22^{\circ} \mathrm{C}$ (termômetro comercial), mas ainda assim um bom resultado.

Realizando o experimento novamente em condições de sala de aula, sem controle de temperatura, obtemos: $T_{g}=3{ }^{\circ} \mathrm{C}$ e $T_{C}=36,5^{\circ} \mathrm{C}$, sendo, portanto, $\Delta T=33,5{ }^{\circ} \mathrm{C}$ em um comprimento de $5,1 \mathrm{~cm}$. Logo, $a \approx 6,6^{\circ} \mathrm{C} / \mathrm{cm}$. Durante os cinquenta minutos de realização do experimento, calibração e obtenção da temperatura ambiente, verificamos pelo termômetro comercial que a temperatura ambiente flutuou entre 27 e $29^{\circ} \mathrm{C}$. O valor obtido pelo termômetro construído foi de $\mathrm{T} \approx$ $25,7^{\circ} \mathrm{C}$, um bom resultado. Pela eq. (5) obtemos para este caso $T_{\text {Erro }}=3,4 \%$, logo $T=(26 \pm 1)^{\circ} \mathrm{C}$.

Diante dos bons resultados e da quantidade de conceitos discutidos, sem dúvidas o termômetro de coluna líquida é um excelente experimento para ser executado em sala de aula.

Fizemos ainda alguns testes para analisar a influência de outras duas substâncias termométricas, água e ar, na obtenção da temperatura ambiente utilizando o mesmo conjunto de parâmetros descritos anteriormente. 


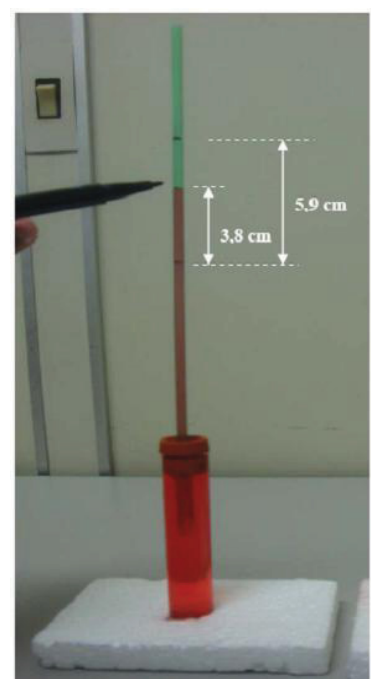

Fig. 17 - Obtenção da temperatura ambiente com o termômetro construído. $T_{A}=5,3{ }^{\circ} \mathrm{C} / \mathrm{cm} \times 3,8 \mathrm{~cm}=20,1^{\circ} \mathrm{C}$. A sala foi climatizada em $22^{\circ} \mathrm{C}$ (termômetro comercial).

No caso da água, tomamos como coeficiente de dilatação térmica a média dos três primeiros valores apresentados na Tabela II, ou seja, $\bar{\gamma}_{\mathrm{H}_{2} \mathrm{O}}=1,68 \times 10^{-4}{ }^{\circ} \mathrm{C}^{1}$, já que estes estão relacionados com o intervalo de temperatura que trabalhamos. Como o coeficiente de dilatação térmica do álcool é $\gamma_{\text {Álcool }}=6,5 \bar{\gamma}_{\mathrm{H}_{2} \mathrm{O}}$, podemos trabalhar com um volume máximo do bulbo de até $\mathrm{V}_{0}=204 \mathrm{ml}$ (eq.3). Dessa forma, é possível a realização do experimento utilizando água como substância termométrica com o bulbo e o canudo nas mesmas dimensões utilizadas para o termômetro com álcool. Contudo, o experimento apresentou sérias desvantagens como, por exemplo, no tempo de calibração. A obtenção de $T_{C}\left(2^{\circ}\right.$ ponto fixo $)$ se deu em, aproximadamente, 50 minutos, enquanto que, para $T_{g}$ ( $1^{\circ}$ ponto fixo), não foi possível registrar com precisão o momento em que a coluna líquida se estabilizou pois, após 3 horas de espera, ainda se observavam variações em sua altura. Portanto, para a execução em sala de aula, o termômetro proposto nesta atividade, com água como substância termométrica, é inviável, corroborando com nossa análise anterior.

Considerando agora o ar, $\gamma_{A r}=3,67 \times 10^{-3}{ }^{\circ} \mathrm{C}^{-1}$, obtemos pela eq. (3) um volume máximo do bulbo de $\mathrm{V}_{0}=9 \mathrm{ml}$. Como o tubo de ensaio que utilizamos tem $\mathrm{V}_{0}=16 \mathrm{ml}$, não foi possível construirmos uma escala no dispositivo, devido à gran- 
de dilatação volumétrica do ar, $\gamma_{A r}=3,3 \gamma_{\text {Álcool }}$. Essa é a mesma justificativa do porque não é possível calibrar o termômetro apresentado no Caderno de Física, uma vez que é sugerido preencher apenas metade do frasco utilizado como bulbo com a substância termométrica.

Pela Fig. 8, nota-se que não tínhamos nenhum frasco com $V_{0} \leq 9 m l$. Para a construção do termômetro de ar, os mesmos cuidados devem ser tomados quanto à obtenção da altura inicial e calibração descritos para o termômetro com álcool. A Fig. 18 ilustra um termômetro desse tipo construído com um pequeno pote plástico de lantejoula $(V=9 \mathrm{ml})$ e um canudo com diâmetro de $4,5 \mathrm{~mm}$, cuja calibração foi feita para $T_{g}=3^{\circ} \mathrm{C}$ e $T_{C}=36,5^{\circ} \mathrm{C}$. O valor obtido para a temperatura ambiente foi de $\mathrm{T}=24^{\circ} \mathrm{C}$, enquanto que a aferição com o termômetro comercial foi de $\mathrm{T}=29^{\circ} \mathrm{C}$. Esta maior diferença em relação ao termômetro com álcool se deve, além dos possíveis erros já discutidos, ao peso da quantidade de água utilizado na coluna de ar como indicador de temperatura (em vermelho na Fig. 18), o qual exerce uma força contrária à da expansão do ar no interior do termômetro. Apesar desse efeito estar presente durante toda a calibração, não podemos afirmar que sua magnitude será a mesma nos dois pontos fixos.

É possível construir um termômetro de ar utilizando apenas um canudo de refresco, porém não é recomendado pelo fato das paredes do canudo serem flexíveis fazendo com que a parte líquida da coluna suba ou desça sem mudanças de temperatura, pelo efeito apenas de pressões aplicadas às suas paredes.

A Fig. 19 mostra alguns termômetros construídos por grupos de alunos do Ensino Médio seguindo um roteiro próprio, baseado nas observações realizadas neste trabalho. Note a variedade de frascos e tubos utilizados. Todos os termômetros foram calibrados de maneira que a temperatura ambiente da sala de aula pudesse ser aferida.

Pela quantidade de conceitos e análises trabalhados, certamente a atividade experimental é um complemento muito interessante para o processo de ensinoaprendizagem de Física, uma vez que esta conduz o aluno ao mundo real, onde são feitas aproximações e mostradas as limitações de determinados modelos comumente tratados de maneira ideal em livros e exercícios didáticos. 


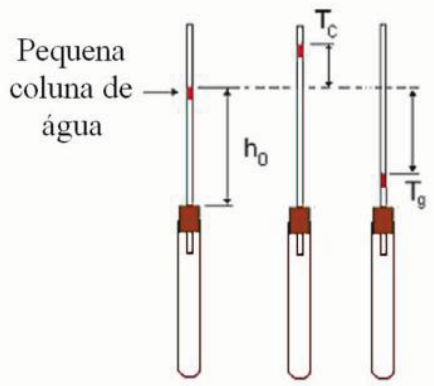

(a)

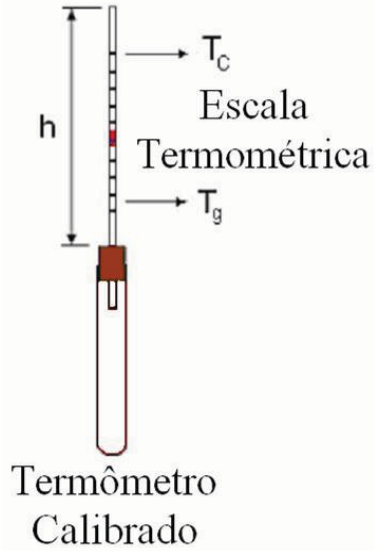

(b)

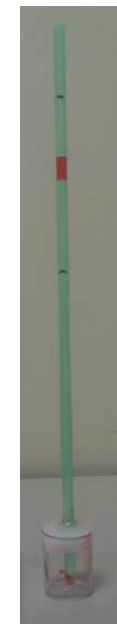

(c)

Fig. 18 - Ilustrações de (a) termômetro de ar mostrando a altura inicial $h_{0}$ e a posição dos pontos fixos $T_{C}$ e $T_{g}$ durante a calibração e (b) termômetro calibrado e com a escala termométrica. É aconselhável utilizar água (em vermelho) para o indicador de temperatura, pois devido à baixa tensão superficial do álcool este se escoa pelo canudo facilmente. (c) Termômetro de ar construído com um pote de lantejoula de $V=9 \mathrm{ml}$.
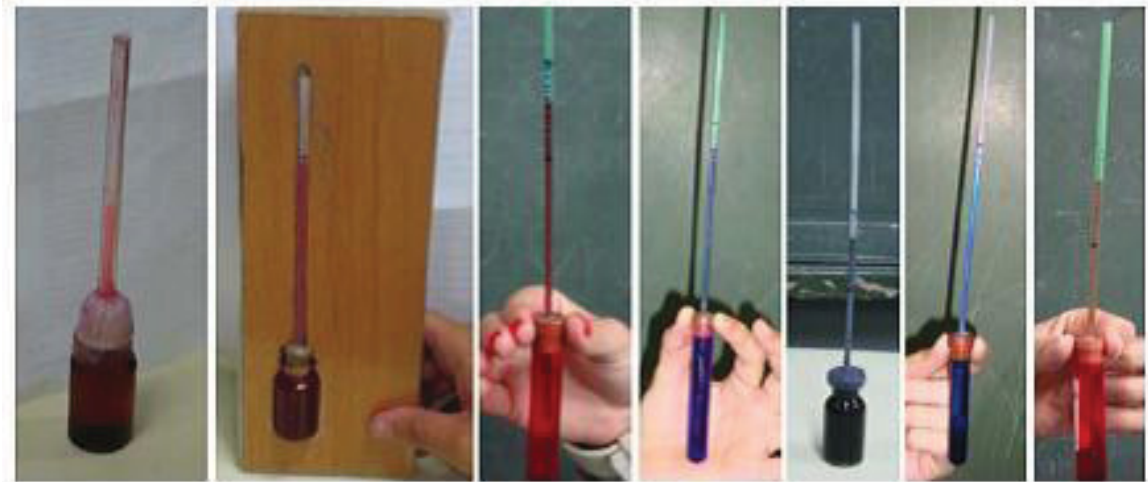

Fig. 19 - Termômetros montados por grupos de alunos da rede pública de ensino, seguindo os procedimentos descritos por um roteiro baseado nas observações feitas neste trabalho. 


\section{Conclusões}

Mostramos, neste trabalho, que mesmo em materiais didáticos considerados de boa qualidade, como é o caso dos Cadernos de Física elaborado pela SEESP, pode-se encontrar roteiros experimentais inadequados. Nesses casos, a atividade experimental pode contribuir negativamente para o processo de ensinoaprendizagem, já que a frustração gerada pelo experimento que não funcionou pode levar o professor a refutar esse tipo de atividade de sua prática docente e os alunos a perderem o interesse por trabalhos experimentais. Nosso objetivo foi incentivar os professores de Física a não desistirem da prática experimental, devido a sua importância, buscando as causas de problemas que alguns experimentos podem apresentar tornando a prática investigativa algo útil para o enriquecimento de suas aulas. Devemos considerar os livros e outros materiais didáticos como objetos norteadores para o trabalho de ensino e não como materiais com argumentos de autoridade.

É importante que os profissionais responsáveis por livros, apostilas e cadernos didáticos ou paradidáticos se atentem para pequenos detalhes que possam parecer irrelevantes, mas que na verdade podem trazer sérias consequências para o ensino de disciplinas científicas, principalmente no Ensino Básico. Nesse sentido, um livro que chamou nossa atenção pela forma e pelo cuidado com que os experimentos foram propostos foi o livro "Experiências de Ciências para o Ensino Fundamental" do professor Alberto Gaspar. Na descrição dos experimentos desse livro, o professor pode encontrar de maneira detalhada os materiais que devem ser utilizados, como se realiza o experimento, o seu funcionamento, o que o aluno deve observar, a explicação e o que pode dar errado na experiência e ainda um item denominado de "Uma Observação a Mais", caso o professor queira complementar a atividade (GASPAR, 2005).

Acreditamos no desenvolvimento e na realização que o professor pode vivenciar se o atributo pesquisador começar a ser incentivado através de atividades investigativas, como a proposta, para designar seu trabalho, pois o profissional que queremos ser depende do pesquisador que somos.

\section{Referências}

ALVES, V. C.; STACHAK, M. A importância de aulas experimentais no processo de ensino aprendizagem em Física: "Eletricidade". In: SIMPÓSIO NACIONAL DE ENSINO DE FÍSICA, 16, 2005. Rio de Janeiro. Anais... Rio de Janeiro: CEFET, 2005. p. 1-4. 
BARBOSA, J. O.; PAULO, S. R.; RINALDI, C. Investigação do papel da experimentação na construção de conceitos em eletricidade no Ensino Médio. Caderno Catarinense de Ensino de Física, v. 16, n. 1, p. 105-122, abr. 1999.

FRADE, R. F.; PAIVA, A. T. Condutividade térmica e calor específico: Química $-1^{\circ}$ Ano. Aveiro: Universidade de Aveiro, 2006.

GASPAR, A. Calor. In: Ática, 2000. cap. 14. p. $307-334$.

GASPAR, A. Experiências de Ciências para o Ensino Fundamental. 1. ed. São Paulo: Ática, 2005. 328p.

HALLIDAY, D.; RESNICK, R.; WALKER, J. Temperatura. In: Fundamentos de Física 2: Gravitação, Ondas e Termodinâmica. 4. ed. Rio de Janeiro: LTC - Livros Técnicos e Científicos Editora S.A., 1993. cap. 19, p. 169-182.

LABURÚ, C. E. Fundamentos para um experimento cativante. Caderno Brasileiro de Ensino de Física, Florianópolis, v. 23, n. 3, p. 382-404, dez. 2006.

MORAES, A. M.; MORAES, L. J. A avaliação conceitual de força e movimento. Revista Brasileira de Ensino de Física, v. 22, n. 2, p. 232-246, jun. 2000.

NETTO, L. F. Feira de Ciências: O imperdível mundo da Física Clássica. Disponível em: <http://www.feiradeciencias.com.br/sala08/08_38.asp>. Acesso em: 12 nov. 2010

PIMENTEL, J. R. Instrumentação para o Ensino de Física: Atividades de Temperatura e Calor. Rio Claro: UNESP/Dep. de Física, 2000. 21 p. Apostila.

SÃO PAULO (Estado). Secretaria da Educação. Fundação para o Desenvolvimento da Educação. Ciências da Natureza e suas Tecnologias - Física: Ensino Médio $2^{\text {a }}$ Série. São Paulo, 2009, v.1. 63 p, Caderno do professor.

SÃO PAULO (Estado). Secretaria da Educação. Fundação para o Desenvolvimento da Educação. Ciências da Natureza e suas Tecnologias - Física: Ensino Médio $2^{\text {a }}$ Série. São Paulo, 2010, v.1, 56 p, Caderno do Aluno. 